\title{
Gender Differences in Multigenerational Caregiving Across the Life Course in Europe
}

Sarah E. Patterson and Rachel Margolis

The University of Western Ontario

Corresponding Author: Sarah E. Patterson, Ph.D., Postdoctoral Fellow, The University of Western Ontario, Sociology Department, Social Science Centre, Room 5306, London, Ontario, Canada, N6A 5C2; spatte45@uwo.ca; (519) 661-2111 ext. 87356

This paper is a part of the Care, Retirement \& Wellbeing of Older People Across Different Welfare Regimes project.

Funding: This work was supported by the Joint Programming Initiative, More Years Better Lives funding from the Canadian Institute of Health Research (MYB-150262) and Social Sciences and Humanities Research Council of Canada (435-2017-0618, 890-2016-9000). 


\title{
Gender Differences in Multigenerational Caregiving Across the Life Course in Europe
}

\begin{abstract}
To better understand how caregiving varies across contexts and the impact of caregiving on social and economic outcomes, we need to understand how it varies across the entire adult life course and how sensitive caregiving estimates are to the inclusion of different directions and types of care. This is the first study to comprehensively describe multigenerational caregiving patterns by gender and age across European countries. We use the Generations and Gender Survey (GGS) Wave $1(\mathrm{~N}=114,147)$ to consider multiple definitions of multigenerational caregiving. In addition to personal care and financial transfers, we also include emotional transfers which are rarely examined. We also examine multigenerational care that includes simultaneous care for any two generations rather than just to parents and children which is most often studied. Across our sample of 11 European countries, we find that women are significantly more likely to give care than men across the life course, and these gender gaps are especially large during critical periods like young adulthood and mid-life around retirement ages. Including emotional caregiving as well as horizontal care (to a spouse, sibling, or friend) are both substantively important in shaping the life course pattern of caregiving and the size of the gender gap. The gender gap in the life course pattern of caregiving have implications for aging, intergenerational inequality, and human capital accumulation across the life course.
\end{abstract}

Keywords: Multigenerational caregiving; sandwiched caregiving; intergenerational transfers; life course; gender 


\section{Introduction}

Multigenerational caregiving, the transfer of resources to at least two different generations, is an important issue for aging populations (Dykstra \& Hagestad, 2016). Caregiving can have positive effects on both the receiver and giver, for example increasing emotional closeness (Rossi \& Rossi, 1990), but it can also have negative implications for the caregiver's own needs and resources (Cohen, Colantonio, \& Vernich, 2002; Lin, Fee, \& Wu, 2012). Negative outcomes can include emotional strain (Fast, Williamson, \& Keating, 1999), strain on ability to work or forced exit from the labor force (Pavalko \& Artis, 1997), and reduced savings and delayed retirement (Meyer, 1990). These negative effects may compound across the life course and can increase insecurity and intergenerational inequality. By providing care to multiple family members simultaneously, multigenerational caregivers may be at the highest risk of negative outcomes because of the cumulative effects from a "caregiving squeeze" (Pavalko, 2011).

Examining patterns of caregiving and multigenerational caregiving by gender and age is important for understanding the ways heavier caregiving duties may disadvantage certain demographic groups over the life course and at critical periods. This may be especially important for understanding the gendered life course in particular, or the ways in which men and women have divergent biographical paths and pacing, linked lives, and turning points which lead to inequality (Moen, 2001). If women are providing simultaneous care to multiple generations during critical periods for developing human capital (Moen, Robison, \& Fields, 1994) and reporting fewer positive outcomes from caregiving (Lin et al., 2012), this may be a source of disadvantage relative to men of similar ages. 
Most existing research on caregiving and gender differences focuses on a limited age range, limiting our ability to see caregiving across the whole life course (Swartz, 2009). The age at which caregivers provide care for family members can have implications for their own wellbeing and ability to save or build human capital (Albertini \& Mencarini, 2014). Caregivers at young ages may be at the greatest risk for long-term consequences and vulnerability (Becker, 2007), and caregivers at older ages are at risk of delayed retirement and reduced savings (Meyer, 1990). Despite the importance of understanding the demography of caregiving across the life course, no descriptive studies document gender differences in caregiving or compare the sensitivity of estimates of caregiving to multiple definitions of caregiving across the entire adult life course.

This study addresses these gaps and answers a call to better count, and thereby value, care work (England, 1992). We do so by examining gender differences in caregiving to one and multiple generations, as well as how the size of the gap is sensitive to the definition of caregiving by type and direction of care. First, we document patterns of caregiving in the last year by country, type of transfer, and direction. We examine the sensitivity of caregiving estimates between definitions used in most studies, which focus on personal care and financial transfers, with those that also include emotional care. This is a significant contribution because emotional care work in general, and particularly within families, is underestimated (Moor \& Komter, 2012; Thoits, 1989), despite its value to families and society (Bengtson \& Roberts, 1991; Rossi \& Rossi, 1990). Second, we evaluate the sensitivity of multigenerational caregiving estimates to the inclusion of horizontal transfers in giving to any two generations, not just upward and downward transfers. This is a significant contribution to the literature which currently treats multigenerational care as only that given to an adult and child (Dukonov \& Zhageni, 2015; 
Wiemers \& Bianchi, 2015), missing additional and potentially costly care given to a spouse, sibling or friend from the same generation. Third, we examine how multigenerational caregiving varies across the life course by gender and age. Gender continues to be a main source of stratification and inequality across the life course (Moen, 1991), thereby highlighting the importance of understanding gender gaps in care. We emphasize how types and directions of care included in the definition can shape the size and pattern of the gender gap in caregiving over the life course.

\section{Types and Direction of Caregiving}

Caregiving is a common part of the life course (Bengtson, Elder, \& Putney, 2005; de Oliveira et al., 2015). Most research analyzes functional transfers, one key part of Bengtson's Intergenerational Solidarity framework (Bengtson, 2001; Bengtson \& Roberts, 1991). These include time spent on personal care for another person (e.g. childcare) and financial transfers. A large empirical literature documents the prevalence of these types of transfer in different contexts, age groups, and time periods. For instance, one quarter of European adults are currently providing personal care to a young, elderly, ill, or disabled family member (Ruppanner \& Bostean, 2014). It is also common for European adults to give help to parents, with one quarter helping with household chores or paperwork in the last year (Deindl \& Brandt, 2011). Among older Europeans (ages 50 and older), 57\% of grandparents provided some grandchild care in the last year (Hank \& Buber, 2009). Financial transfers are uncommon, with less than three percent giving upward transfers across Europe (Deindl \& Brandt, 2011).

Affective transfers, or listening to another person's problems or emotions, is another key part of Bengtson's Intergenerational Solidarity framework (Bengtson, 2001; Bengtson \& Roberts, 1991). Population-level empirical studies of emotional transfer in families are rare 
(Moor \& Komter, 2012; Sarkisian \& Gerstel, 2004) even though emotional care is imbedded in and integral to basic family functioning (Erickson, 1993; Thoits, 1989). This is likely because many population-based household surveys include questions about personal care or financial transfers but not emotional transfers. Emotional transfers are important to measure because they are "invisible" labor, often not counted as work (Erikson, 1993) despite being vital for personal and family functioning, including solidarity (Bengtson \& Roberts, 1991) and bonding (Rossi \& Rossi, 1990). Lack of emotional support is linked to adverse health outcomes, including loneliness and heart conditions in older age (Sorkin, Rook, \& Lu, 2002). Emotional work at home can spillover into the caregiver's workplace and is associated with reduced well-being and increased stress (Wharton \& Erickson, 1995). Importantly, emotional labor is stratified by gender and measures of caregiving that omit it may underestimate gender differences (Hochschild, 1983). There is little data analysis on emotional transfers, but a Dutch study found that the vast majority $(84 \%)$ of Dutch adults gave emotional transfers when measured by personal interest in another's person life over the last three months (Schenk \& Dykstra, 2012).

The types of care given depend on the direction of care. Downward transfers are the most common across the life course in Europe, even until the oldest ages (Albertini \& Mencarini, 2014; Daatland \& Lowenstein, 2005; Swartz, 2009), but decline over time (Kalmijn, 2018). This pattern is found in many contexts, including in the U.S. where adult caregivers give $78.3 \%$ of care downward to adult children (Longacre, Valdmanis, Handorf, \& Fang, 2016). Providing personal care and financial transfers upward to parents is found to be uncommon (Albertini, Kohli, \& Vogel, 2007; McGarry \& Schoeni, 1995), but caring for a spouse is especially common as people age (de Oliveira et al., 2015). 
Despite a large body of research on intergenerational transfers, very few studies cohesively document patterns of caregiving by type and direction over the entire adult life course in Europe (for recent example using broad care measures, see Kotowska, 2010). Importantly, emotional care work is often not measured and thereby undercounted in most estimates of caregiving. Adding to problems with comparison, estimates of caregiving are not easily comparable from one country or study to another because question wording and definitions vary widely across studies. We fill these gaps by using a dataset that has comparable questions across many countries and includes different types of care for both men and women across the entire life course.

\section{Multigenerational Caregiving}

Multigenerational caregiving is providing simultaneous care for family members of two generations. It is particularly important when investigating caregiving across the life course because of the "squeeze" (Pavalko, 2011) it causes for those who care, with potential consequences for building and maintaining human capital during critical periods. Most research on multigenerational caregiving has focused on the "sandwich generation" a term coined in the early 1980s to refer to the middle-aged Baby Boom generation with elderly parents and dependent children (Pierret, 2006). Because "sandwiched" caregiving measures only include care given to children and parents (Loomis \& Booth, 1995) or more broadly an adult and child (Dukonov \& Zhageni, 2015), most studies have focused on samples of middle age and older adults (Grundy \& Henretta, 2006; Margolis \& Wright, 2017). This leaves a gap regarding how common it is to provide care to multiple generations during early adulthood.

Given recent demographic changes, it makes sense to examine multigenerational caregiving to any two generations rather than focusing on the generations just above and below 
the caregiver. Increasing life expectancy and "longer years of shared lives" with family members (Bengtson, 2001) increases the potential years to provide care. Today's multigenerational caregivers may be caring for grandchildren and their parents simultaneously, instead of their children and parents (Dykstra, 2013). Longer years of shared lives also increase the importance of horizontal caregiving or giving to those in the same generation such as a spouse, sibling, or friend. Longer life expectancy for men (World Health Organization, 2018) may mean that spousal care is becoming an increasingly important and critical part of multigenerational caregiving for both men and women. Caring for siblings could become more important in the future as the population of older adults without a partner or children increases (Margolis \& Verdery, 2017; Verdery \& Margolis, 2017), and siblings share longer lives together (Uhlenberg, 1980). Siblings may become especially important for emotional care (Connidis \& Campbell, 1995; Miner \& Uhlenberg, 1997).

Existing research on multigenerational caregiving has not yet examined how the prevalence of this type of caregiving or gender differences are sensitive to the inclusion of providing care to a horizontal tie (e.g. sibling, spouse, or friend), or to the inclusion of emotional care. Most studies of multigenerational caregiving focus on time and financial transfers and older adults (Margolis \& Wright, 2017). Including horizontal transfers and emotional transfers are likely important to understanding gendered patterns of multigenerational caregiving, since, for instance, women are more likely to give emotional transfers to siblings than men (Connidis \& Campbell, 1995; Miner \& Uhlenberg, 1997) and more likely to provide care to a partner (Spillman \& Pezzin, 2000). Given the longer years of shared lives across family members and the importance of emotional caregiving to family solidarity and well-being, we fill these 
identified gaps in the literature by measuring both across multiple countries for both men and women across the life course.

\section{The Demography of Caregiving over the Life Course}

When in the life course is caregiving most common? In Europe, caregiving for children or grandchildren peaks between the ages of 35 to 49 -year-olds. Among mid to later life adults in Europe, those ages $65+$ are the most likely to perform help with personal tasks to family members or friends (Bonsang, 2007; Jang, Avendano, \& Kawachi, 2012). In the U.S., being the primary caregiver for an older adult age 65 and older is most common among those who are also older themselves ( $27.3 \%$ of 65 to 74 year olds) and least common among those ages 14 to 34 (2.2\%) (Spillman \& Pezzin, 2000). Young caregivers have received little attention despite the fact that in the U.S., over half of 19-30 year olds gave support to a parent in the form of either emotional care, household help, or a financial transfer (Eggebeen, 2005).

Because most studies of sandwiched caregiving focus on older samples, this leaves us without any knowledge about how common multigenerational caregiving is among younger adults (Dykstra, 2013). From what we do know among older adults, between one quarter and one third of older adults, ages 50 and older, in Europe provide sandwiched care (Grundy \& Henretta, 2006). Using U.S. time use data and focusing on giving to any child and any adult simultaneously, Dukhovnov and Zagheni (2015) find that care for children is most common in young adulthood at higher rates for young women in addition to care for older adults. This suggests that multigenerational care may vary across the life course in more ways than currently captured in literature that uses limited age samples and definitions of care.

The fact that women give care more often than men across the life course is thought to contribute to unequal access to resources and responsibilities (Moen et al., 1994; Moen, 2001). 
Women aged 35 to 49 are the most likely to care for children or the elderly in Europe (Kotowska, 2010). Two-thirds of women 35-49 and 54\% of women 25-34 provide child or grandchild care at least several days per week (Eurofound, 2017). In the U.S., women are more likely to provide sandwiched care except at the oldest ages (Margolis and Wright, 2017), when gender gaps in care narrow, close, or switch (Agree \& Glaser, 2009; Kahn, McGill, \& Bianchi, 2011; OECD, 2011). Although gender gaps in caregiving have been established at particular points in the life course (Rossi \& Rossi, 1990), no studies that we are aware of have measured gender differences in caregiving across all of adulthood.

\section{The Current Study}

This study makes three main contributions. First, we compare estimates of caregiving with the inclusion of emotional care and without, an often-understudied aspect of caregiving. Second, we examine the sensitivity of estimates of multigenerational caregiving to the types of generations to which care is given. We include horizontal care as one of the two possible generations and compare with traditional definitions of sandwiched care that focus on upward and downward transfers. Third, we estimate gender differences in caregiving across the life course across multiple dimensions in order to provide comparable estimates of care by gender and age group. Overall, these three contributions help to understand caregiving's role in the gendered life course and "caregiving squeeze" among adults in Europe.

\section{Data}

We use data from Wave 1 of the Generations and Gender Survey (GGS), which was collected between 2003 and 2013. The GGS is the best source of data for this project because it provides comparable, nationally representative data for the adult population in many European 
countries and includes questions about different forms and directions of care for both men and women. More information about each country's survey is available in Appendix Table A1. We include countries in our sample that met the following criteria. First, we include countries that surveyed a broad age range of 18-80 (this excluded Austria). Second, we include countries with questions about at least two of the following three types and directions of transfers: personal care, financial transfers, and emotional transfers (this excluded Hungary, Italy, Estonia, and the Netherlands). Third, we include countries and cases with valid GGS weights (this excluded Romania). This yields a sample of 11 countries of the 17 possible in the first wave of the GGS: Belgium, Bulgaria, Czech Republic, France, Georgia, Germany, Lithuania, Norway, Poland, Russia, and Sweden ( $\mathrm{N}=125,733)$. Less than four percent of observations were missing on our variables of interest ${ }^{1}$; therefore, we use a casewise deletion sample $(\mathrm{N}=114,147)$. We conduct a sensitivity analysis using multiply imputed data and find that estimates and statistical significance for gender differences are similar.

We examine three directions of caregiving: upward, horizontal, and downward. Respondents report different types of transfers for up to five individuals, ${ }^{2}$ therefore, a respondent could provide transfers of each kind by any direction. Upward transfers include a mother, father, mother of partner, father of partner, grandmother, or grandfather. Horizontal transfers include a partner/spouse, sister, brother, friend/neighbor/colleague, or previous partner. Downward transfers include general childcare, general grandchild care, general care for other children, or

\footnotetext{
${ }^{1}$ When taking into account countries that did not inquire about particular items.

${ }^{2}$ Personal care could be reported for 10 individuals, financial transfers for up to 6 , and up to 7 for emotional transfers. Transfers for more than 5 people were extremely rare (for instance, only 2 cases for personal care, none for financial and 229 for emotional care - or less than $0.2 \%$ of the total original sample for emotional care). Therefore, a cap on 5 persons was used across all items for consistency. Analysis with all cases show no difference in results.
} 
personal care for a son, daughter, stepson, stepdaughter, granddaughter, grandson, or partner of a child.

We examine three types of caregiving over the last 12 months: personal care, financial transfers, and emotional transfers. For personal care, respondents giving any of the following are counted as caregiving: "personal care such as eating, getting up, dressing, bathing, or using toilets;" helping with any childcare tasks, including: dressing, putting to bed, illness, leisure, homework, transportation; "childcare to other people;" and "help to look after your grandchild(ren)." For financial transfers, respondents answer: "have you or your partner/spouse given for one time, occasionally, or regularly money, assets, or goods of substantive value to a person outside the household? Please think also about land and property you or your partner/spouse transferred during this time." For emotional transfers, respondents answer: "has anyone talked to you about his/her personal experiences and feelings?" For each type of transfer, respondents list to whom they gave.

We use information about the three types of caregiving (personal care, financial transfers, and emotional transfers) given either upward, horizontal, or downward to create two measures of multigenerational caregiving. First, "sandwiched" caregiving is when respondents give to those above and below them, the most traditional definition of multigenerational care. Second, our more inclusive measure captures a respondent caring for at least two different generations of family members or friends/colleagues/neighbors, including upward, downward, and horizontal, simultaneously. 


\section{Method}

First, we describe the prevalence and directions of caregiving across all ages by country (Table 1). Second, we illustrate how the life course pattern of caregiving varies by direction, gender and age across all countries in our sample, contrasting the exclusion of emotional care and not (Figures 1A, 1B). Third, we test the sensitivity of including emotional transfers in a definition of multigenerational caregiving, in addition to testing the sensitivity of expanding multigenerational caregiving from the traditional "sandwiched" definition to one that includes two generations of any direction for each country (Table 2). Fourth, we illustrate how the life course pattern of multigenerational caregiving varies by gender and age across all countries, dependent on definition of multigenerational caregiving and inclusion of emotional care (Figures 2A, 2B). Last, we estimate a series of adjusted, weighted predicted probabilities of providing multigenerational care using logistic regression models, controlling for country and survey year, with gender and age interactions (Table 3). All estimates are weighted to be nationally representative.

\section{Results}

Table 1 examines the types of care that respondents provide horizontally, downward, and upward. Emotional support is the most common type of horizontal caregiving (to a partner, sibling or friend). Across the 11 countries, $58.5 \%$ of adults provide horizontal emotional support, ranging from eight in ten in Norway to $36.7 \%$ in the Czech Republic. Giving personal or financial support horizontally is much less common (1.9\% and 1.6\% respectively). Downward caregiving is the next most common direction of care, and this category is dominated by childcare. One in four adults $(24.7 \%)$ provides care to their own child, almost one in five 
(19.4\%) provides grandchild care, and one in eight (13.0\%) provides care to "other" children. Besides childcare, downward emotional transfers are the next largest category of care (14.4\%), followed by financial transfers (4.1\%), and personal help (0.5\%). For upward transfers, emotional care is the most common type of transfer (15.6\%) followed by personal help (3.8\%), and financial help (1.0\%). Across all the countries in our sample, emotional caregiving and horizontal transfers are substantial categories, and their inclusion will greatly affect estimates of caregiving.

Next, we examine how caregiving in each direction varies over the life course, and how the patterns differ by gender. Figure 1A documents the prevalence of caregiving including only personal care and financial transfer, and Figure 1B includes personal care, financial transfers, and emotional transfers. First, we examine downward caregiving. In both figures, downward transfers follow an "M" pattern for both men and women, where most respondents provide care in young adulthood and then again in middle age. The levels of downward transfers are slightly higher when including emotional transfers, but overall, downward transfers are well captured by including only personal care and financial transfers.

Women are more likely to provide downward care throughout the life course until older ages when differences decline to seven percentage points among those 70-74. Interestingly, the direction of the gender gap in downward caregiving is consistent across the two definitions of care, but the inclusion of emotional care widens the magnitude of the gap in middle and older ages. For instance, the gender gap in downward care is a four percentage point difference for those 45-49 in Figure 1A, but widens to a nine percentage point difference in Figure 1B. This suggests that emotional support is an important component of the caregiving that women provide to their children, even at older ages. No matter whether or not emotional transfers are included, 
the largest gender gap in downward care is at ages 25-29, a 31-percentage point difference $(\mathrm{p}<.001)$

Next, we examine horizontal and upward transfers in Figures 1A and 1B. Horizontal and upward caregiving are not very common throughout the life course when including just personal care and financial transfer (Fig 1A). Among men, the percentage providing horizontal care ranges from $2.3 \%$ and $5.5 \%$, and for women the numbers are similar (2.4\% to $6.2 \%)$. Upward care ranges from $0.4 \%$ to $5.0 \%$ for men, and from $0.4 \%$ to $8.8 \%$ for women, depending on age. Horizontal transfers are uncommon but increase over the life course, peaking at ages 70-74 for women (6.2\% providing care) and at age $75-80$ for men (5.5\% providing care). Upward care, when including just personal and financial transfer, peaks for women at ages 50-54 and 55-59 (8.8\% for both) and for men between $45-49(5.0 \%)$.

The gender gaps in horizontal and upward caregiving are hugely underestimated without including emotional transfers (Figure 1B). Including all three types of transfers increases the frequency of horizontal and upward caregiving across the life course. When we include emotional transfers, the higher level of caregiving performed by women early in the adult life course is dramatic, reaching $70.6 \%$ for horizontal caregiving (11-percentage point greater than men) and $36.8 \%$ for upward care (14-percentage point greater than men) for women 18 to 24 $(\mathrm{p}<.001)$

Next, we turn to multigenerational caregiving. Table 2 presents the percentage of adults who gave care to at least two generations in the last year by country. Countries are ordered by the prevalence of "sandwiched" caregiving, defined as giving to generations above and below simultaneously. Percentages providing care for the more traditionally studied categories of transfers (personal and financial only) are presented first, followed by all types (personal, 
financial, and emotional transfers). Among adults in our sample, only $2.4 \%$ are considered sandwiched caregivers of personal care and financial transfers in the last year. Accounting for emotional care increases sandwiched caregiving across the life course by five times, with one in ten $(10.3 \%)$ providing personal care, financial, or emotional care to kin in generations above and below them. These results show that emotional transfers account for a large portion of sandwiched caregiving.

Turning to a broader definition of multigenerational care in Table 2, estimates of multigenerational caregiving are almost four times larger when including caring in any two directions. Our broadest definition of care shows that $40 \%$ of respondents in all countries participate in multigenerational caregiving in the last year. Even including only personal care and financial transfers, there is still a substantial increase when we examine caregiving to any two generations, compared to sandwiched caregiving. Accounting for personal care, financial, and emotional transfers, causes a tenfold increase in the prevalence of multigenerational caregiving compared to only accounting for personal care and financial transfers. Table 2 reaffirms the importance of measuring emotional transfers and simultaneous care in any two directions when estimating multigenerational caregiving.

Next, we examine how caregiving and multigenerational caregiving vary across the life course by gender. First, we can see how the patterns of any caregiving varies by gender and age. In Figure 2A, including only personal care and financial transfers, we see an "M" shaped curve over the life course where any caregiving peaks at ages $30-34$ at $81.4 \%$ for women and at ages 35-39 at $63.2 \%$ for men. This then declines in the mid $40 \mathrm{~s}$ but increases slightly again at ages $60-$ 64 for women and 65-59 for men. Any type and direction of caregiving is more common for women than men across the life course $(\mathrm{p}<.001)$, except at the oldest ages of $75-80$. Gender gaps 
are largest in young adulthood at ages 18-34 - peaking at a 29-percentage point different for those 25-29, a 25-percentage point different for 30-34, and 18-percentage point difference for those 18-24). Gender differences for providing any care are statistically significant for all ages $(\mathrm{p}<.001)$ except 70-74.

Comparing Figure 2B to 2A, we see that estimates of caregiving are substantially higher when we include emotional transfers, and the age patterns shift. Inclusion of emotional transfers keeps levels of caregiving across the life course above $70 \%$ for women and $65 \%$ for men, respectively, except at the very oldest ages (75-80). In 2B, any caregiving peaks at 30-34 (94.0\%) for women and 35-39 (82.0\%) for men, over a 12-percentage point increase for women at this age and almost a 19-percentage point difference for men of this age. This comparison reaffirms the importance of measuring emotional care for understanding caregiving by both men and women across the life course.

Next, we can examine the life course pattern of sandwiched caregiving and multigenerational caregiving (giving to any two generations). In Figure 2A, patterns of multigenerational caregiving, when including just personal care and financial transfers, are low throughout the life course. For sandwiched care, rates for women range between 3 and 4 percent across most of the life course (from 25 to 64 years old), peaking at 4.3\% for those 30-34 and 3539. For men's sandwiched care, rates range between 1-2\% across the life course (from 25 to 69 years old), peaking at $2.3 \%$ for those $40-44$. The levels of multigenerational caregiving are slightly higher than for sandwiched for both men and women, but the differences are not that large, and the gender patterns are not very different, instead ranging from 4-6\% for women and 2-3\% for men across most of the life course. Even though levels are generally low, gender 
differences for both sandwiched and multigenerational care are significant across the life course $(p<.001)$ except at $75-80$ for sandwiched care.

In Figure 2B, when we include emotional transfers, different patterns appear over the life course and much larger gender gaps emerge. Both definitions of multigenerational caregiving peak in young adulthood and then slowly decreases as age increases for men and women. Caregiving is much more prevalent when we include care to any two generations, rather than just the older and younger generations (sandwiched), which emphasizes the importance of including horizontal generations to clearly understand the "caregiving squeeze." For women ages 30 to 34, one-in-four $(26.7 \%)$ are sandwiched and this increases to almost two of three (64.8\%) when including giving in any two directions for personal, financial, or emotional care. For men ages 35 to 39 , one in six (12.5\%) are sandwiched, compared to over two in five (45.4\%) being multigenerational caregivers. Comparing Figure $2 \mathrm{~B}$ to $2 \mathrm{~A}$ illustrates the importance of including emotional transfers for understanding multigenerational caregiving for both men and women across the life course, with a 58-percentage point increase for women in multigenerational care and 41-percentage point increase for men, at their respective peaks. Finally, regarding gender differences in Figure 2B, gaps are largest in young adulthood with a 15-percentage point difference for those 30-34 and sandwiched and 23-percentage point difference at 25-29 for multigenerational care. Gender gaps are wider for multigenerational care among middle age, compared to sandwiched care, and both definitions remain significant for the majority of the life course $(\mathrm{p}<.001)$.

Last, we further test the size of the gender gaps in the predicted probability of providing care by age group and for four definitions of multigenerational care with some simple multivariate models (Table 3, full models shown in Appendix Table A2). These findings echo 
the descriptive findings shown above. The size of the gender gaps in caregiving are largest with the broadest definitions of multigenerational care, and smallest with the narrowest measures. This is due to the huge gender gap in emotional caregiving. Including emotional transfers is also important for capturing a large gender gap early in the life course, where the gap is twice as large for multigenerational caregiving (for any two generations) than sandwiched caregiving. Sensitivity Analysis

To test the robustness of our analysis, we completed several additional analyses. First, we included only countries with all of the caregiving questions and the results are similar to those presented in the main text. Next, we tested the sensitivity of the results to missing individual level data by using multiple imputation (chained imputation, $M=10$ ), and we found similar patterns of results. Differences in gender gaps do not exceed 1-percentage point difference and gender differences continue to be significant at roughly the same levels across the life course. Next, we examined the gender by age patterns for each country individually and found that the patterns were similar across countries for definitions that measure emotional care with an exception of Sweden, which did not ask about direction of emotional care. There was variation across countries when emotional care was not included, mirroring variation seen by country in our original analysis. Last, we examined how sensitive horizontal multigenerational caregiving estimates were to the inclusion of non-family members (friends, neighbors, or colleagues). Overall, results are similar. Removing friends reduces care overall by both men and women, but removal shows that women are more likely to be caring for friends across the life course and especially at older ages. Additionally, while men give more care at older ages with the removal of friends, they are also more likely to be married and giving to a spouse. 


\section{Discussion}

This study is the first to provide estimates of multigenerational caregiving across the life course using multiple types of caregiving and directions of care. Previous research on multigenerational care has often focused on limited age ranges of caregivers or narrow definitions of care, mainly investigating those who only give transfers to generations above and below them, and personal care and financial transfers only. Our findings show that multigenerational caregiving, measured as giving to any two generations in the last year, is most common during early adulthood, though it occurs frequently throughout the life course.

Additionally, not accounting for emotional caregiving greatly underestimates general caregiving rates, men's caregiving specifically, and gender differences across the life course. Across all measures of caregiving, women are more likely than men to provide care to multiple family members across the life course except at the very oldest ages. Our findings reaffirm that without measuring various forms of care and including all generations in multigenerational care, we may be missing important "squeezing" contributing to the gendered life course.

Research has firmly established that caregiving is often undercounted and thereby undervalued (England, 1991; Folbre, 2002). Our findings highlight the importance of how caregiving is defined and measured (Emery \& Mudrazija, 2015), especially emotional care (Bengtson, 2001; Bengtson \& Roberts, 1991; Moor \& Komter, 2012), for understanding the costs of providing care across the life course. Our results show that young adults are providing a lot of emotional support upward to parents or other older family members, and women in the middle ages report high levels of emotional care downward for children or other younger family members. Given the magnitude of emotional transfers by both men and women across the life 
course, we urge scholars to work to better understand this type of caregiving and to include it in more surveys.

Our findings highlight the importance of horizontal care in measuring the "caregiving squeeze" (Pavalko, 2011) of multigenerational care. Our estimates are larger compared to other European estimates (Kotowska 2010), but our measures use more specific language and include more combinations of care. With longer years of shared lives, we argue that we cannot fully understand multigenerational caregiving if we omit horizontal care. Good measurement is important for valuing care (Emery \& Mudrazija, 2015; England, 1992). For instance, a recent study estimates that the cost to replace informal caregiving of older family members with formal care would be over $\$ 17 \mathrm{~K}$ year (Cecchini, 2017); this cost would only be larger for those giving to multiple family members at once.

Third, our results echo previous work documenting that women are more likely than men to be caring at each life course stage (Robards, Vlachantoni, \& Evandrou, 2015), with some exceptions at the end of the life course (Agree \& Glaser, 2009; OECD, 2011). Gender gaps are largest at critical periods of the life course in relation to human capital: at the youngest ages of adulthood and in the middle years. This has important implications for women's ability to gain human capital across the life course and can help to gauge and better understand the gendered life course (Moen, 2001). For instance, if women are spending large portions of their lives caregiving, and potentially out of the labor force, this could help us understand later life inequalities like women's higher rates of poverty at older ages (Rank \& Hirscl, 1999). More research is needed to understand the nexus of individual, family, institutional ,and structural influences on caregiving (Moen \& DePasquale, 2017) given that social policies influence women's participation in care, but not men's (Haberkern, Schmid, \& Szydlik, 2015). 
By including diverse definitions of caregiving across the life course and using a population based survey of both men and women, our study also responds to critiques of caregiving literature that argue men's care is not captured (Bookwala, Newman, \& Schulz, 2005). Our measurements have important implications for both men and women. For women, large amounts of emotional care, alongside other forms of care, may be a large contributor to the gendered life course, or the ways in which men and women's lives are unequal (Moen, 1991). Emotional care is also important for men's lives, especially for men's integration into families and their own emotional well-being (Erickson, 1993). In our sensitivity analyses, we reaffirm the importance and levels of emotional care taking place, showing that men report giving similar or even higher levels of care to partners later in the life course, while women do important emotional work for both family and friends. Understanding multigenerational care and gender differences has important implications for assessing family care needs in workplace and state level policies (Bogenschneider, 2000; Phyllis Moen \& DePasquale, 2017). Overall, the undercounting and undervaluing of caregiving across the life course mutes the contributions of women and clouds the understanding of greater rates of caregiving's effect on their lives.

Finally, caregiving is intertwined with demographic characteristics of populations. It is important to understand when in the life course caregivers are being "squeezed" as fertility, morbidity, and mortality patterns in these countries shift over time (Albertini \& Mencarini, 2014; Herlofson \& Hagestad, 2011; Leopold \& Skopek, 2015; Zagheni \& Wagner, 2015) and how patterns may also vary by socioeconomic status within countries (Margolis \& Wright, 2017). It is important to enumerate and track caregiving occurring early in the life course to better understand how cumulative effects, both positive and negative, may build over times for caregivers, especially those in young adulthood (Becker, 2007; Hunt, Levine, \& Naiditch, 2005). 
As multigenerational relationships continue to be important for families (Bengtson, 2001) and populations continue aging, it is critical to understand the timing of caregiving over the life course. Future research could consider understanding multiple and coinciding roles throughout the life course (e.g. labor force participation) and further explore the demographic explanatory mechanisms behind caregiving across the life course (Albertini, 2016; Puur, Sakkeus, Põldma, \& Herm, 2011).

The Generations and Gender survey is valuable because it is the only source that provides cross-country comparisons across the life course for both men and women. However, our study has some limitations. Not all countries fielded all questions and the personal care question is limited to Activities of Daily Living, the most extreme form of care. Both of these limitations mean that our estimates of caregiving may be conservative. A second limitation is that is the questions ask about caregiving "in the last year," which leaves us unable to provide estimates for how common it is to provide multigenerational care over a larger time period, or to pinpoint any episodic or long-term care. We are encouraged by the call for datasets to collect more family and caregiving data longitudinally (Seltzer, 2015). Similar to other datasets, the survey only asks about up to four generations, which may underestimate intergenerational families (Dykstra et al., 2016). Finally, co-residence can be a source of transfer, but we did not include it here because it is difficult to tease apart who is supporting whom (Dykstra, 2010). This could be an area for future research.

Our study emphasizes the importance of measurement for understanding levels of caregiving and especially gender differences. We hope that our descriptive data can be used for researchers who might want to compare their estimates of caregiving in a particular direction, 
type or age group to the levels examined here, and to what extent estimates might differ if different data were available. We encourage comparison with other studies and surveys. 


\section{References}

Agree, E. M., \& Glaser, K. (2009). Demography of Informal Caregiving. In Uhlenberg (Ed.), International Handbook of Population Aging (pp. 648-668). Dordrecht: Springer. https://doi.org/10.1007/978-1-4020-835

Albertini, M. (2016). Ageing and Family Solidarity in Europe: Patterns and Driving Factors of Intergenerational Support. World Bank Policy Research Working Paper, (May), 1-40. Retrieved from https://papers.ssrn.com/sol3/papers.cfm?abstract_id=2781299\#\#

Albertini, M., Kohli, M., \& Vogel, C. (2007). Intergenerational transfers of time and money in European families: common patterns — different regimes? Journal of European Social Policy, 17(4), 319-334. https://doi.org/10.1177/0958928707081068

Albertini, M., \& Mencarini, L. (2014). Childlessness and support networks in later life: New pressures on familistic welfare states?. Journal of Family Issues, 35(3), 331-357. https://doi.org/10.1177/0192513X12462537

Becker, S. (2007). Global perspectives on children's unpaid caregiving in the family: Research and policy on "young carers" in the UK, Australia, the USA and sub-Saharan Africa. Global Social Policy, 7(1), 23-50. https://doi.org/10.1177/1468018107073892

Bengtson, V. (2001). The Burgess Award Lecture: Beyond the nuclear family: The increasing importance of multigenerational bonds. Journal of Marriage and Family, 63(1), 1-16.

Bengtson, V. L., Elder Jr., G. H., \& Putney, N. M. (2005). The Life Course Perspective on Ageing: Linked Lives, Timing, and History. In M. L. Johnson (Ed.), The Cambridge Handbook of Age and Ageing (pp. 521-529). Cambridge, MA: Cambridge University Press. 
Bengtson, V. L., \& Roberts, R. E. L. (1991). Intergenerational Solidarity in Aging Families: An Example of Formal Theory Construction. Journal of Marriage and the Family, 53(4), 856. https://doi.org/10.2307/352993

Bogenschneider, K. (2000). Has Family Policy Come of Age? A Decade Review of the State of U.S. Family Policy in the 1990s. Journal of Marriage and Family, 62(November), 11361159.

Bonsang, E. (2007). How do middle-aged children allocate time and money transfers to their older parents in Europe? Empirica, 34(2), 171-188. https://doi.org/10.1007/s10663-0079034-3

Bookwala, J., Newman, J. L., \& Schulz, R. (2005). Methodological Issues in Research on Men Caregivers. In Men as Caregivers (pgs. 69-98). Amherst, New York: Prometheus Books. Cecchini, M. (2017). The hidden economics of informal elder-care in the United States. Journal of the Economics of Ageing. Retrieved from https://www.sciencedirect.com/science/article/pii/S2212828X1630055X (online only). https://doi.org/10.1016/j.jeoa.2017.04.002

Cohen, C. A., Colantonio, A., \& Vernich, L. (2002). Positive aspects of caregiving: Rounding out the caregiver experience. International Journal of Geriatric Psychiatry, 17(2), 184188. https://doi.org/10.1002/gps.561

Connidis, I. A., \& Campbell, L. D. (1995). Closeness, Confiding, and Contact Among Siblings in Middle and Late Adulthood. Journal of Family Issues, 16(6), 722-745.

Daatland, S. O., \& Lowenstein, A. (2005). Intergenerational solidarity and the family-welfare state balance. European Journal of Ageing, 2(3), 174-182. https://doi.org/10.1007/s10433005-0001-1 
de Oliveira, G. R., Neto, J. F., de Camargo, S. M., Lucchetti, A. L. G., Espinha, D. C. M., \& Lucchetti, G. (2015). Caregiving across the lifespan: Comparing caregiver burden, mental health, and quality of life. Psychogeriatrics, 15(2), 123-132. https://doi.org/10.1111/psyg.12087

Deindl, C., \& Brandt, M. (2011). Financial support and practical help between older parents and their middle-aged children in Europe. Ageing and Society, 31(04), 645-662. https://doi.org/10.1017/S0144686X10001212

Dukhovnov, D., \& Zagheni, E. (2015). Who takes care of whom in the U.S.? Evidence from matrices of time transfer by age and sex. Population and Development Review, 41(2), 183206. https://doi.org/10.1111/j.1728-4457.2015.00044.x.

Dykstra, P. A. (2010). Intergenerational Family Relationships in Ageing Societies. United Nations Economic Commission for Europe. Retrieved from https://repub.eur.nl/pub/21973/. https://doi.org/10.1016/B978-0-08-024456-3.50001-X

Dykstra, P. A., Bühler, C., Fokkema, T., Petric, G., Platinovšek, R., Kogovšek, T., \& Hlebec, V. (2016). Social network indices in the Generations and Gender Survey: An appraisal. Demographic Research, 34(1), 995-1036. https://doi.org/10.4054/DemRes.2016.34.35

Dykstra, P. A., \& Hagestad, G. O. (2016). How demographic patterns and social policies shape interdependence among lives in the family realm. Population Horizons, 13(2). https://doi.org/10.1515/pophzn-2016-0004

Dykstra, P. A. (2013). Ties that Bind: Families across Time and Space - Uhlenbeck Lecture 31, 29. Retrieved from https://www.nias.knaw.nl/Publications/Uhlenbeck Lecture/31_Pearl Dykstra 
Eggebeen, D. J. (2005). Cohabitation and Transfers of Support. Social Forces, 83(3), 10971110.

Emery, T., \& Mudrazija, S. (2015). Measuring intergenerational financial support: Analysis of two cross-national surveys. Demographic Research, 33, 951.

England, P. (1992). Comparable Worth: Theories and Evidence. New York: Routledge.

Erickson, R. J. (1993). Reconceptualizing Family Work: The Effect of Emotion Work on Perceptions of Marital Quality. Journal of Marriage and the Family, 55(4), 888. https://doi.org/10.2307/352770

Eurofound. (2017). European Quality of Life Survey 2016: Quality of life, quality of public services, and quality of society. Luxembourg. Retrieved from https://www.eurofound.europa.eu/surveys/european-quality-of-life-surveys/europeanquality-of-life-survey-2016

Fast, J. E., Williamson, D. L., \& Keating, N. C. (1999). The Hidden Costs of Informal Elder Care. Journal of Family and Economic Issues, 20(3), 301-326.

Folbre, N. (2002). The Invisible Heart: Economics and Family Values. New York: The New Press.

Grundy, E., \& Henretta, J. C. (2006). Between elderly parents and adult children: A new look at the intergenerational care provided by the "sandwich generation." Ageing and Society, 26(5), 707-722. https://doi.org/10.1017/S0144686X06004934

Haberkern, K., Schmid, T., \& Szydlik, M. (2015). Gender differences in intergenerational care in European welfare states. Ageing \& Society, 35(2), 298-320. 
Hank, K., \& Buber, I. (2009). Grandparents Caring for Their Grandchildren: Findings from the 2004 Survey of Health, Ageing, and Retirement in Europe. Journal of Family Issues, 30(1), 53-73. https://doi.org/10.1177/0192513X08322627

Herlofson, K., \& Hagestad, G. O. (2011). Challenges in moving from macro to micro: Population and family structures in ageing societies. Demographic Research, 25, 337-370. https://doi.org/10.4054/DemRes.2011.25.10

Hochschild, A. (1983). The Managed Heart: Commercialization of Human Feeling. Berkely, CA: University of California Press.

Hunt, G., Levine, C., \& Naiditch, L. (2005). Young Caregivers in the U.S.: Findings from a National Survey. National Alliance for Caregiving, (September), 1-59. Retrieved from http://www.caregiving.org/data/youngcaregivers.pdf

Jang, S. N., Avendano, M., \& Kawachi, I. (2012). Informal caregiving patterns in Korea and European countries: A cross-national comparison. Asian Nursing Research, 6(1), 19-26. https://doi.org/10.1016/j.anr.2012.02.002

Kahn, J. R., McGill, B. S., \& Bianchi, S. M. (2011). Help to family and friends: Are there gender differences at older ages? Journal of Marriage and Family, 73(1), 77-92. https://doi.org/10.1111/j.1741-3737.2010.00790.x

Kalmijn, M. (2018). The Effects of Ageing on Intergenerational Support Exchange: A New Look at the Hypothesis of Flow Reversal. European Journal of Population, 1-22.

Kotowska, I. E. (2011). Second European Quality of Life Survey: Family life and work. Retrieved from https://www.eurofound.europa.eu/publications/report/2010/quality-of-lifesocial-policies/second-european-quality-of-life-survey-family-life-and-work 
Leopold, T., \& Skopek, J. (2015). The delay of grandparenthood: A Cohort comparison in East and West Germany. Journal of Marriage and Family, 77(2), 441-460. https://doi.org/10.1111/jomf.12169

Lin, I., Fee, H. R., \& Wu, H. (2012). Negative and Positive Caregiving Experiences: A Closer Look at the Intersection of Gender and Relationships. Family Relations, 61(2), 343-358. https://doi.org/10.1111/j.1741-3729.2011.00692

Longacre, M. L., Valdmanis, V. G., Handorf, E. A., \& Fang, C. Y. (2016). Work Impact and Emotional Stress Among Informal Caregivers for Older Adults. The Journals of Gerontology Series B: Psychological Sciences and Social Sciences, 72(3), 522-531. https://doi.org/10.1093/geronb/gbw027

Loomis, L. S., \& Booth, A. (1995). Multigenerational Caregiving and Well-Being: The Myth of the Beleaguered Sandwich Generation. Journal of Family Issues, 16(2), 131-148. https://doi.org/0803973233

Margolis, R., \& Verdery, A. M. (2017). Older Adults Without Close Kin in the United States. Journals of Gerontology - Series B Psychological Sciences and Social Sciences, 72(4), 688-693. https://doi.org/10.1093/geronb/gbx068

Margolis, R., \& Wright, L. (2017). Older Adults With Three Generations of Kin: Prevalence, Correlates, and Transfers. The Journals of Gerontology Series B: Psychological Sciences and Social Sciences, 72(6), 1067-1072. https://doi.org/10.1093/geronb/gbv158

McGarry, K., \& Schoeni, R. F. (1995). Transfer Behavior in the Health and Retirement Study: Measurement and the Redistribution of Resources within the Family. The Journal of Human Resources, 30, S184-S226. 
Meyer, M. H. (1990). Family status and poverty among older women: The gendered distribution of retirement income in the United States. Social Problems, 37(4), 551-563.

Miner, S., \& Uhlenberg, P. (997). Intragenerational Proximity and the Social Role of Sibling Neighbors after Midlife. Family Relations, 46(2), 145-153.

Moen, P. (2001). The gendered life course. In R. H. Binstock \& L. K. George (Eds.), Handbook of Aging and the Social Sciences (pp. 179-196). San Diego, CA: Academic Press.

Moen, P., \& DePasquale, N. (2017). Family care work: a policy-relevant research agenda. International Journal of Care and Caring, 1(1), 45-62. https://doi.org/10.1332/239788217X14866284542346

Moen, P., Robison, J., \& Fields, V. (1994). Women's work and caregiving roles: a life course approach. Journal of Gerontology, 49(4), S176-S186. https://doi.org/10.1093/geronj/49.4.S176

Moor, N., \& Komter, A. (2012). The impact of family structure and disruption on intergenerational emotional transfer in Eastern Europe. European Journal of Ageing, 9(2), 155-167. https://doi.org/10.1007/s10433-011-0207-3

OECD. (2011). The Impact of Caring on Family Carers. In Help Wanted? Providing and Paying for Long-Term Care. Retrieved from https://www.oecd.org/els/healthsystems/47884865.pdf. https://doi.org/10.1162/ISEC

Pavalko, E. K. (2011). Caregiving and the life course: Connecting the personal and the public. In Handbook of sociology of aging (pp. 603-616). Springer, New York, NY.

Pavalko, E. K., \& Artis, J. E. (1997). Women's caregiving and paid work: causal relationships in late midlife. The Journals of Gerontology. Series B, Psychological Sciences and Social Sciences, 52(4), S170-S179. 
Pierret, C. R. (2006). The "sandwich generation": women caring for parents and children. Monthly Labor Review, 129(September), 2006.

Puur, A., Sakkeus, L., Põldma, A., \& Herm, A. (2011). Intergenerational family constellations in contemporary Europe: Evidence from the generations and gender survey. Demographic Research, 25, 135-172. https://doi.org/10.4054/DemRes.2011.25.4

Rank, M. R., \& Hirschl, T. A. (1999). Estimating the proportion of Americans ever experiencing poverty during their elderly years. The Journals of Gerontology Series B: Psychological Sciences and Social Sciences, 54(4), S184-S193.

Robards, J., Vlachantoni, A., \& Evandrou, M. (2015). Informal caring in England and Wales Stability and transition between 2001 and 2011. Advances in Life Course Research, 24, 21-33. https://doi.org/10.1016/j.alcr.2015.04.003

Rossi, A. S., \& Rossi, P. H. (1990). Of Human Bonding: Parent-Child Relations Across the Life Course. New York, NY: Aldine de Gruyter.

Ruppanner, L., \& Bostean, G. (2014). Who cares? Caregiver well-being in Europe. European Sociological Review, 30(5), 655-669. https://doi.org/10.1093/esr/jcu065

Sarkisian, N., \& Gerstel, N. (2004). Explaining the gender gap in help to parents: The importance of employment. Journal of Marriage and Family, 66(2), 431-451. https://doi.org/10.1111/j.1741-3737.2004.00030.x

Schenk, N., \& Dykstra, P. A. (2012). Continuity and change in intergenerational family relationships: An examination of shifts in relationship type over a three-year period. Advances in Life Course Research, 17(3), 121-132. https://doi.org/10.1016/j.alcr.2012.01.004 
Seltzer, J. A. (2015). Intergenerational family support processes from young adulthood through later life: Do we need a new national survey? Journal of Economic and Social Measurement, 40, 231-247. https://doi.org/10.3233/JEM-150403

Sorkin, D., Rook, K. S., \& Lu, J. L. (2002). Loneliness, Lack of emotion, lack of companionship, and the Likelihood of having a hearts condition in an elderly sample. Annals of Behavioral Medicine, 24(4), 290-298.

Spillman, B. C., \& Pezzin, L. E. (2000). Potential and Active Family Caregivers: Changing Networks and the 'Sandwich Generation.' The Milbank Quarterly, 78(3), 347-374. https://doi.org/10.1111/1468-0009.00177

Swartz, T. T. (2009). Intergenerational family relations in adulthood: Patterns, variations, and implications in the contemporary United States. Annual Review of Sociology, 35(1), 191212. https://doi.org/10.1146/annurev.soc.34.040507.134615

Thoits, P. A. (1989). The sociology of emotions. Annual Review of Sociology, 15(1), 317-342. https://doi.org/10.2307/2083229

Uhlenberg, Peter. (1980). Death and the Family. Journal of Family History 5 (3): 313-20.

Verdery, A. M., \& Margolis, R. (2017). Projections of white and black older adults without living kin in the United States, 2015 to 2060. Proceedings of the National Academy of Sciences, 201710341. https://doi.org/10.1073/pnas.1710341114

Wharton, A. S., \& Erickson, R. J. (1995). The Consequences of Caring: Exploring the Links between Women's Job and Family Emotion Work. The Sociological Quarterly, 36(2), 273-296. 
Wiemers, E. E., \& Bianchi, S. M. (2015). Competing Demands from Aging Parents and Adult Children in Two Cohorts of American Women. Population Development and Review, 41(1), 127-146. https://doi.org/10.1111/j.1728-4457.2015.00029.x.Competing

World Health Organization. (2018). Life expectancy. Retrieved from http://www.who.int/gho/mortality_burden_disease/life_tables/situation_trends_text/en/

Zagheni, E., \& Wagner, B. (2015). The impact of demographic change on intergenerational transfers via bequests. Demographic Research, 33, 525-534.

https://doi.org/10.4054/DemRes.2015.33.18 
Table 1. Percentage of adults, ages 18 to 80 , providing different forms of care by direction in the last year by country

\begin{tabular}{|c|c|c|c|c|c|c|c|c|c|c|c|c|}
\hline & \multicolumn{3}{|c|}{ Horizontal } & \multicolumn{6}{|c|}{ Downward } & \multicolumn{3}{|c|}{ Upward } \\
\hline & 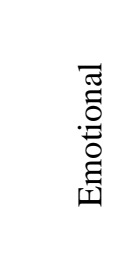 & 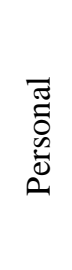 & 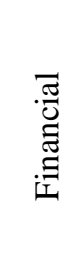 & 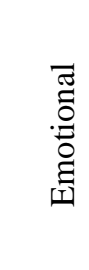 & $\begin{array}{l}\bar{Z} \\
\tilde{0} \\
0 \\
\vdots \\
0 \\
0\end{array}$ & 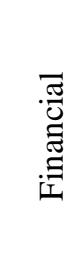 & 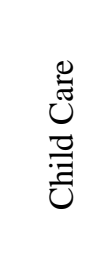 & 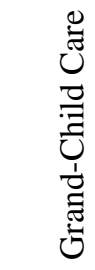 & 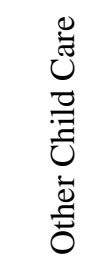 & 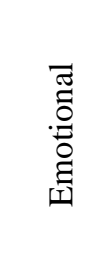 & 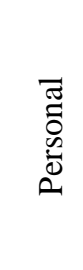 & 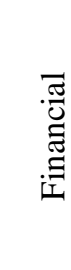 \\
\hline Sweden* & n.a. & 1.8 & 1.6 & n.a. & 0.3 & 4.9 & 23.0 & 22.3 & n.a. & n.a. & 2.6 & 0.4 \\
\hline Germany* & 46.9 & 1.6 & 0.4 & 8.6 & 0.2 & 2.8 & 20.0 & n.a. & 7.6 & 6.9 & 2.7 & 0.8 \\
\hline Lithuania* & 52.6 & 1.4 & n.a. & 13.7 & 0.6 & n.a. & 22.5 & 11.3 & 7.9 & 15.0 & 2.9 & n.a. \\
\hline Georgia & 63.5 & 2.1 & 4.4 & 14.4 & 0.5 & 1.5 & 22.6 & 16.1 & 7.5 & 13.2 & 4.8 & 0.8 \\
\hline Bulgaria & 59.5 & 2.0 & 0.5 & 15.1 & 0.4 & 1.3 & 20.4 & 31.8 & 7.8 & 13.1 & 3.9 & 0.3 \\
\hline Poland* & 53.6 & 1.6 & 1.5 & 12.7 & 0.4 & 4.8 & 27.4 & n.a. & 9.9 & 14.4 & 4.5 & 1.3 \\
\hline Czech Republic & 36.7 & 1.3 & 0.6 & 12.2 & 0.9 & 1.7 & 21.4 & 18.8 & 6.6 & 19.7 & 3.3 & 0.4 \\
\hline Belgium & 62.1 & 1.7 & 0.9 & 9.4 & 0.6 & 1.6 & 30.8 & 0.1 & 14.0 & 18.6 & 3.5 & 0.7 \\
\hline France* & 63.4 & 1.9 & 2.0 & 10.4 & 0.4 & 7.2 & 25.0 & n.a. & 25.6 & 17.1 & 2.4 & 1.8 \\
\hline Russia & 63.0 & 2.4 & 2.7 & 20.4 & 0.8 & 6.3 & 23.3 & 24.7 & 16.8 & 17.5 & 5.3 & 2.6 \\
\hline Norway* & 79.0 & 2.7 & 1.1 & 23.3 & 0.8 & 6.9 & 32.9 & n.a. & 26.1 & 21.0 & 4.4 & 0.5 \\
\hline Total & 58.5 & 1.9 & 1.6 & 14.5 & 0.5 & 4.1 & 24.7 & 19.4 & 13.0 & 15.6 & 3.8 & 1.0 \\
\hline
\end{tabular}

Note: n.a.= not asked

*Lithuania did not inquire about financial transfers; Sweden did not inquire about direction of emotional transfers; Germany, Poland, France, and Norway did not inquire about grandchild care. 
Table 2. Percentage of adults, ages 18-80, providing care to at least two different directions in the last year by country

\begin{tabular}{|c|c|c|c|c|c|}
\hline & & \multicolumn{2}{|c|}{$\begin{array}{c}\text { Sandwiched } \\
\text { (Down and Up Only) }\end{array}$} & \multicolumn{2}{|c|}{$\begin{array}{c}\text { Multigenerational } \\
\text { (At Least Two: Up, Down } \\
\text { Horizontal) }\end{array}$} \\
\hline & $\mathrm{N}$ & $\begin{array}{l}\text { Personal and } \\
\text { Financial }\end{array}$ & $\begin{array}{l}\text { Personal, } \\
\text { Financial, } \\
\text { Emotional }\end{array}$ & $\begin{array}{c}\text { Personal } \\
\text { and Financial }\end{array}$ & $\begin{array}{l}\text { Personal, } \\
\text { Financial, } \\
\text { Emotional }\end{array}$ \\
\hline Sweden* & 5,584 & 1.5 & 1.5 & 2.9 & 2.9 \\
\hline Germany* & 9,172 & 1.2 & 4.3 & 1.7 & 24.8 \\
\hline Lithuania* & 9,863 & 1.2 & 8.4 & 1.8 & 35.1 \\
\hline Georgia & 9,997 & 2.6 & 8.6 & 5.4 & 41.3 \\
\hline Bulgaria & 12,108 & 2.1 & 8.6 & 3.7 & 43.5 \\
\hline Poland* & 19,573 & 2.5 & 9.9 & 3.8 & 37.8 \\
\hline Czech Republic & 8,621 & 1.7 & 11.2 & 2.6 & 31.8 \\
\hline Belgium & 5,533 & 2.0 & 12.5 & 2.9 & 42.1 \\
\hline France* & 9,724 & 2.2 & 12.1 & 4.0 & 45.3 \\
\hline Russia & 11,094 & 4.8 & 14.8 & 7.6 & 50.2 \\
\hline Norway* & 12,878 & 2.9 & 16.8 & 4.8 & 63.1 \\
\hline Total & 114,147 & 2.4 & 10.3 & 3.9 & 40.2 \\
\hline
\end{tabular}


Table 3. Adjusted predicted probability of providing care by gender and age group from weighted logistic regression models with a gender and age interaction, controlling for country and survey year

\begin{tabular}{|c|c|c|c|c|}
\hline \multicolumn{5}{|c|}{ Age Group } \\
\hline & $18-34$ & $35-49$ & $50-64$ & $65-80$ \\
\hline \multicolumn{5}{|c|}{ Sandwiched Caregiving (personal and financial transfers) } \\
\hline Men & $1.1 \%(0.9-1.3)$ & $2.0 \%(1.7-2.3)$ & $1.8 \%(1.5-2.0)$ & $0.5 \%(0.3-0.6)$ \\
\hline Women & $2.8 \%(2.5-3.2)$ & $3.4 \%(3.0-3.8)$ & $3.4 \%(3.0-3.8)$ & $0.8 \%(0.6-1.0)$ \\
\hline Gap & $1.8 * * *$ & $1.4 * * *$ & $1.6 * * *$ & $0.3^{* *}$ \\
\hline \multicolumn{5}{|c|}{ Multigenerational Caregiving (personal and financial transfers) } \\
\hline Men & $2.4 \%(2.1-2.7)$ & $3.3 \%(2.9-3.7)$ & $2.8 \%(2.4-3.1)$ & $2.1 \%(1.8-2.5)$ \\
\hline Women & $4.2 \%(3.8-4.7)$ & $4.8 \%(4.3-5.2)$ & $5.1 \%(4.6-5.6)$ & $2.9 \%(2.6-3.3)$ \\
\hline Gap & $1.8 * * *$ & $1.5 * * *$ & $2.3 * * *$ & $0.8 * * *$ \\
\hline \multicolumn{5}{|c|}{ Sandwiched Caregiving (personal, financial or emotional transfers) } \\
\hline Men & $5.9 \%(5.4-6.3)$ & $8.6 \%(8.0-9.2)$ & $4.2 \%(3.8-4.6)$ & $1.1 \%(0.9-1.3)$ \\
\hline Women & $16.9 \%(16.2-17.7)$ & $15.8 \%(15.1-16.6)$ & $8.0 \%(7.5-8.5)$ & $1.4 \%(1.2-1.7)$ \\
\hline Gap & $11.0 * * *$ & $7.2 * * *$ & $3.8 * * *$ & $0.3 *$ \\
\hline \multicolumn{5}{|c|}{$\begin{array}{l}\text { Multigenerational Caregiving (personal, financial or emotional } \\
\text { transfers) }\end{array}$} \\
\hline Men & $27.8 \%(26.9-28.6)$ & $33.5 \%(32.6-34.3)$ & $24.8 \%(24.0-25.7)$ & $22.4 \%(21.4-23.4)$ \\
\hline Women & $50.3 \%(49.5-51.2)$ & $46.6 \%(45.8-47.5)$ & $35.9 \%(35.1-36.8)$ & $22.2 \%(21.4-23.1)$ \\
\hline Gap & $22.5 * * *$ & $13.1 * * *$ & $11.1 * * *$ & 0.2 \\
\hline
\end{tabular}


Figure1. Percentage of respondents by gender and age providing different directions of care in the last year among all countries

1A: includes personal and financial transfers

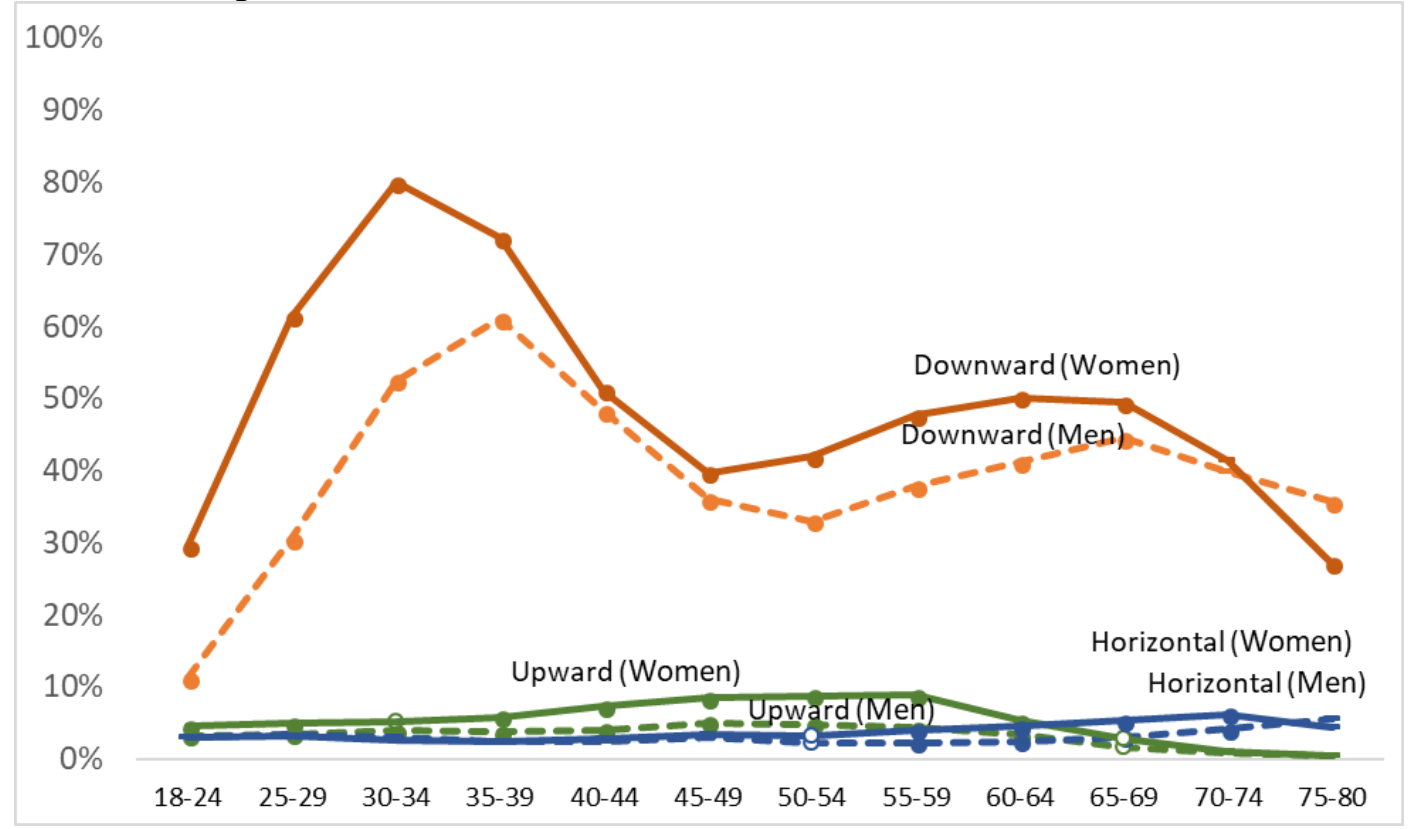

Figure 1B: includes personal, financial and emotional transfers

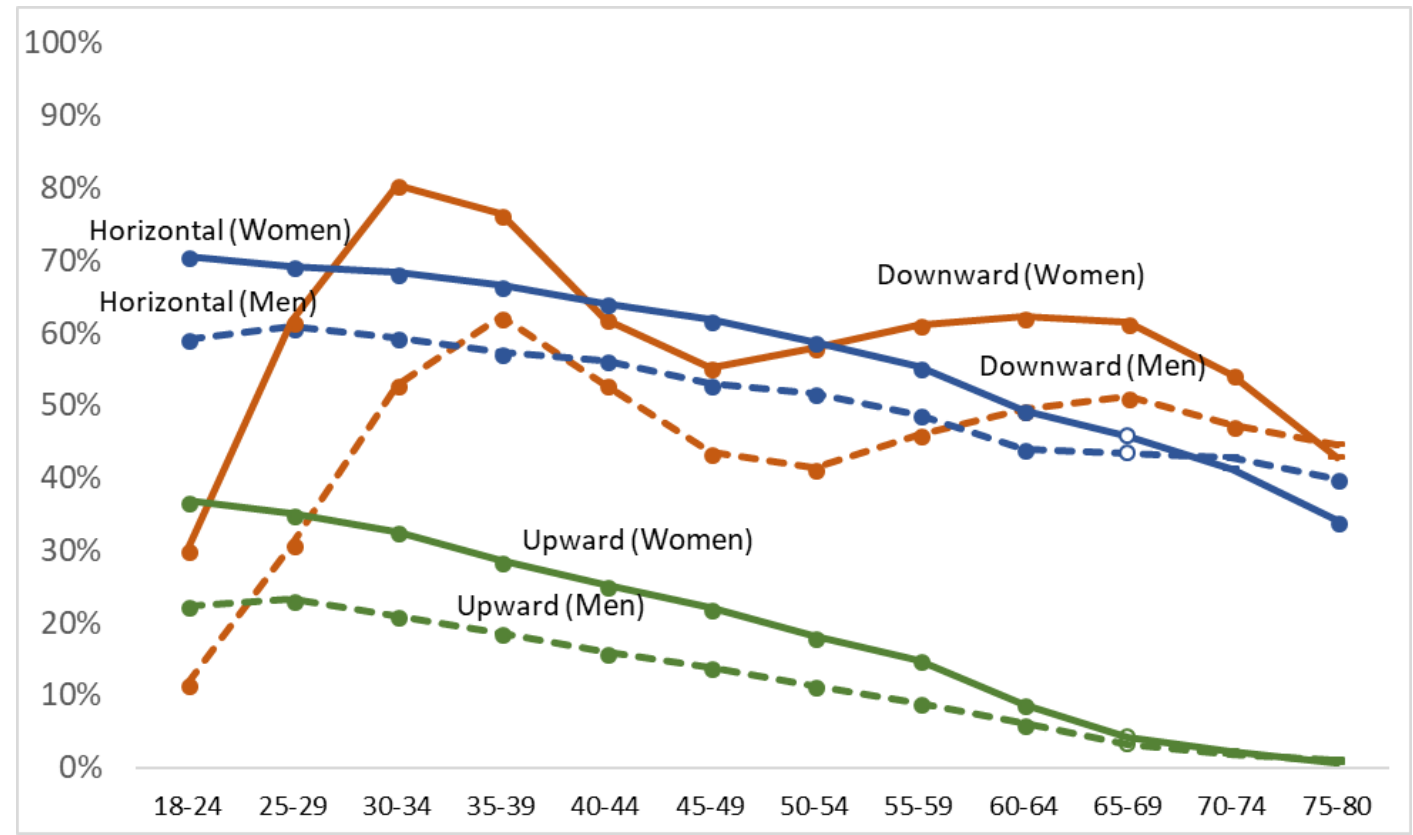

Note: Gender difference within each age group and direction indicated by markers. Solid circles $=\mathrm{p}<.001$, empty circles $=\mathrm{p}<.05$, no circle $=$ not significant. 
Figure 2. Percentage of respondents by gender and age providing any care and multigenerational care in the last year among all countries

2A: includes personal and financial transfers

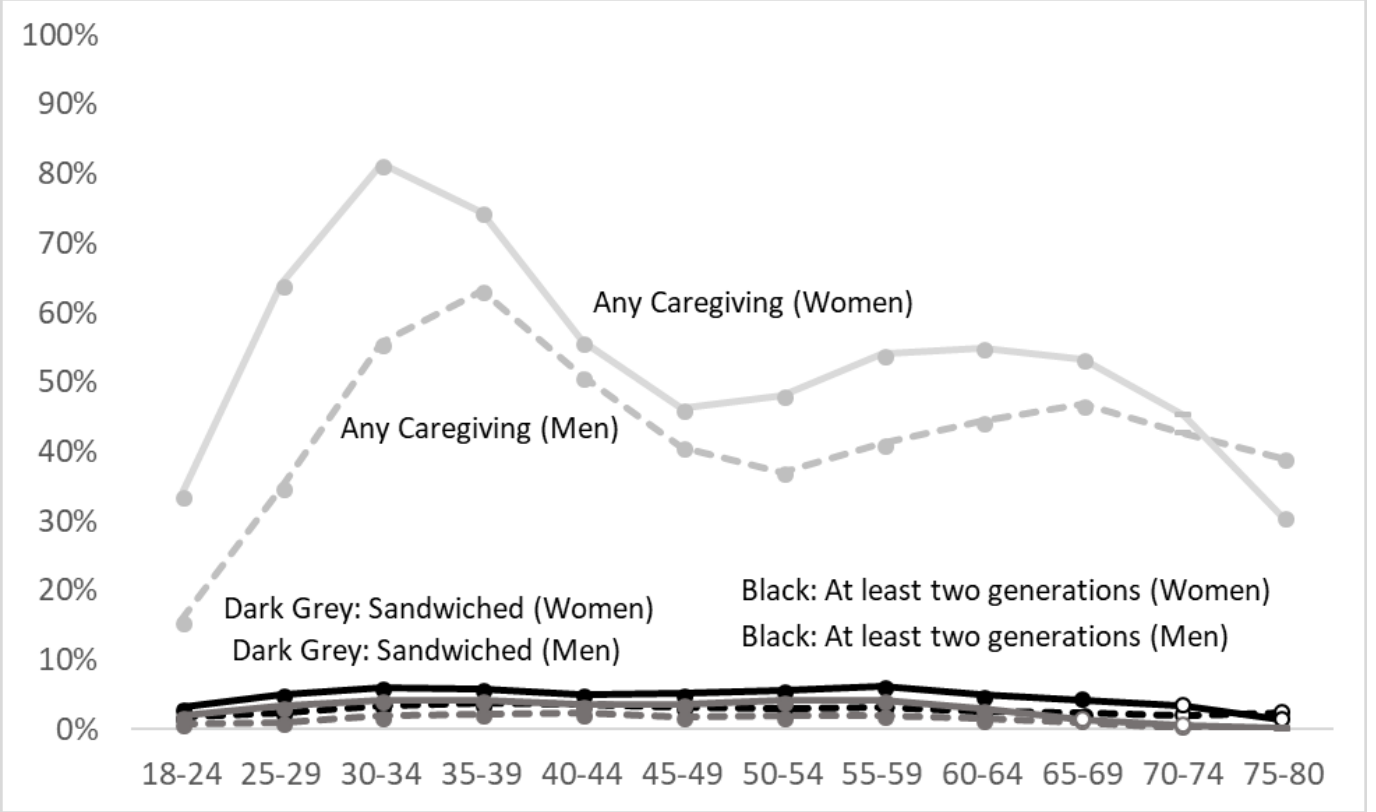

2B: includes personal, financial and emotional transfers

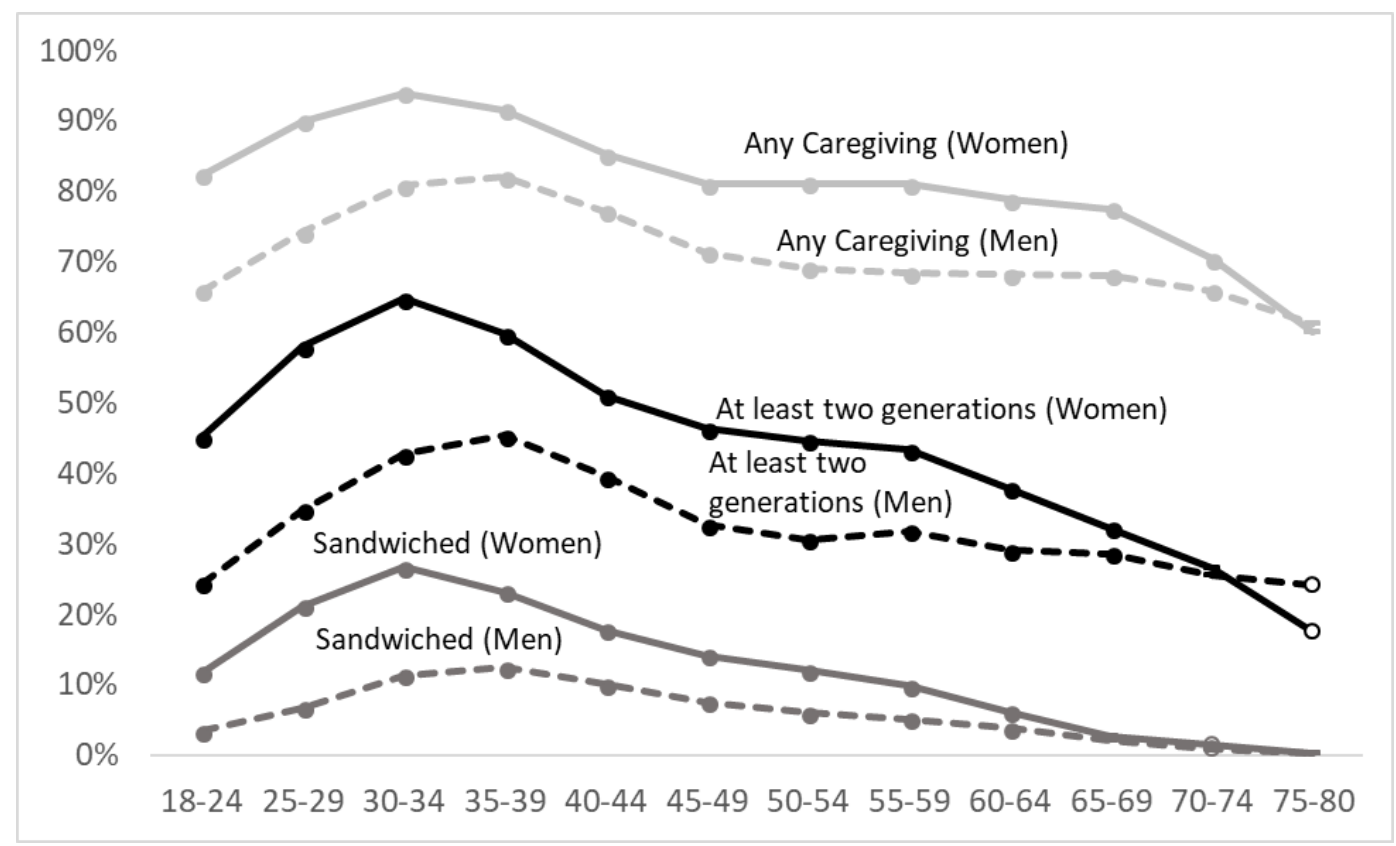

Note: Gender difference within each age group indicated by markers. Solid circles $=\mathrm{p}<.001$, empty circles $=\mathrm{p}<.05$, no circle $=$ not significant. 